\title{
Chimney Cleaning and Inspection Robot
}

\author{
Peter Marcinko ${ }^{1}$, Ivan Virgala' , Lubica Miková', Erik Prada' ${ }^{1}$, Tatiana Kelemenová1, Michal \\ Kelemen ${ }^{1, *}$ and Martin Varga ${ }^{1}$
}

1 Technical University of Košice, Faculty of Mechanical Engineering, Letná 9, 04200 Košice

\begin{abstract}
The paper deals with robot, which locomotes inside chimney for cleaning and inspection purposes. Carbon particles are in sediments on inner chimney wall. Chimney has to be periodically cleaned and inspected because of fire risk. Paper introduces concept of service robot for this application. Tracked locomotion has been selected as principle of locomotion inside chimney.
\end{abstract}

Keywords: robot, chimney, locomotion, mechatronics.

\section{Introduction}

The aim of the paper is to design concept of robot for cleaning and inspection of chimney. Chimney is for offtake of exhaust gas from combustion process inside heater device like fireplace, fire oven or fire heating boiler. Normally, cleaning and inspection of chimney are executed by chimney sweeper manually on house-top. Chimney sweeper has to climb on house-top and there is a dangerous of side-slip and falling-down accident during the work. Using of the robot eliminates this risk. Inspection can be executed through the service door placed inside house. Chimney sweeper will only sit and control of robot through the joystick on operator panel and check it on LCD screen. Inspection process is sensed via using of CCD camera and it can be stored in video file as documentation from service work. Heater device is connected to the chimney through the T-joint, which can be as problem for robot locomotion inside chimney [1-7].

The robot should be used as teleoperation system with some automatic functions. Requirements can be summarized as follow:

$\checkmark$ robot has to locomote through the T-joint inside chimney,

$\checkmark$ robot has to adapt to inner diameter of chimney and adjust normal force between the locomotion segment and inner pipe wall,

$\checkmark$ robot has to detect end of the chimney and stop locomotion,

$\checkmark$ robot has to be unlocked in case of failure for ease pulling out,

$\checkmark$ robot has to have any system for damage protection during the falling down in case of failure.

\section{Principle of the proposed robot}

Robot will consist of minimum of two modules and every module will have three tracked segments arranged at $120^{\circ}$ around the robot body. Tracked modules are connected to robot frame through the spring joint. Spring is used as vibration damper. The proposed robot has to overcome T-joint and also cross-section with non-constant inner diameter and also technological scraps (glue and cement). Design of robot is planned for own weight, traction force (applied to cleaner brush) and this loading will be assumed for obtaining of desired friction forces between the tracks and inner chimney wall. Traction force is identified from experiments and weight is estimated on the base of preliminary robot design. 
Tracked segment (fig. 1) has been designed. The segment includes also DC motor with gearing and conical gearing. Frame consist of thin aluminium sheets and also tightening mechanism for preloading of track. DC motor has 10 times bigger torque than required moment, because it is necessary to have reserve of power for variable diameter and obstacles inside chimney. The driven shaft is checked via using of FEM (finite element method). Stress and deformation in shaft are less then limit values.
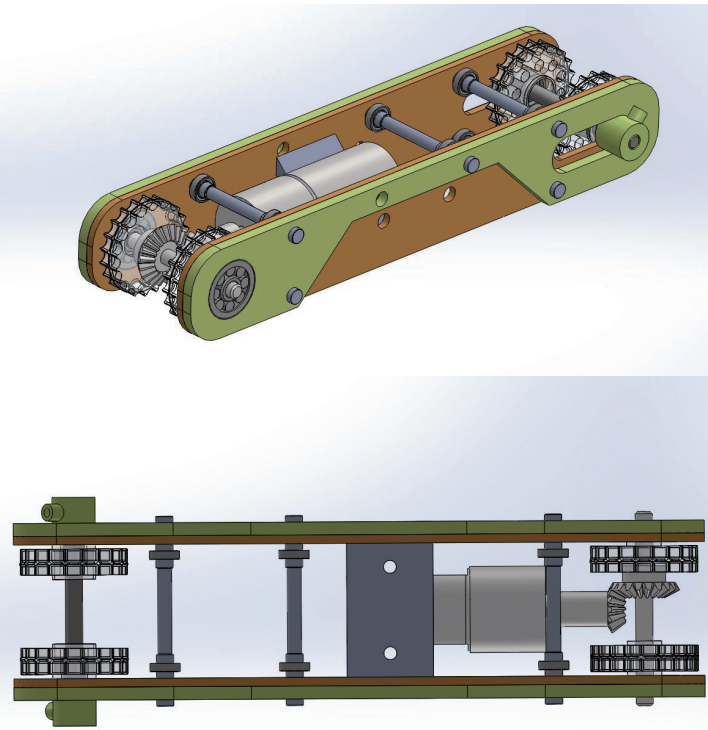

Fig. 1: Tracked segment for robot.
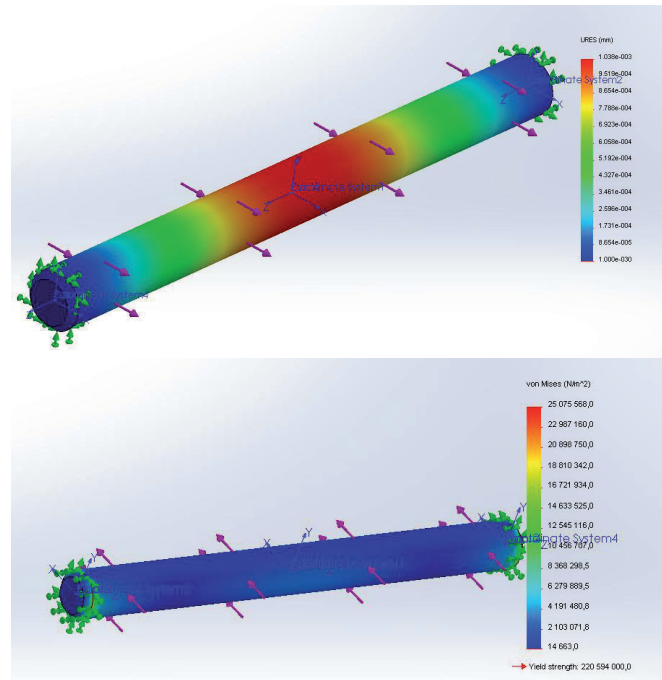

Fig. 2: Displacement and stress on driven shaft of tracked segment.

\section{Geometry of proposed robot undercarriage}

Every tracked segment should be pressed to inner chimney wall because of required friction force and normal force between track and inner chimney wall. For ensuring of stability, the double parallelogram is designed for carrying of tracked segment (fig. 3).
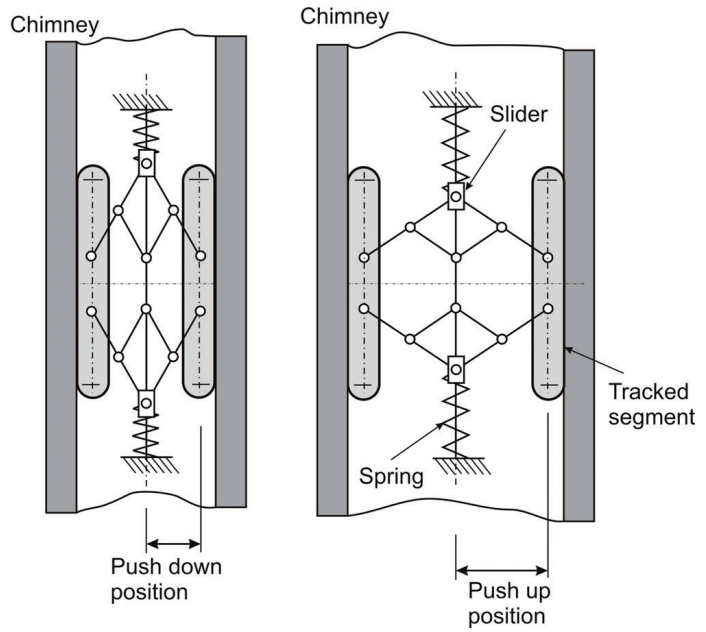

Fig. 3: Tracked segment geometry.

The task to design robot for locomotion inside chimney is complicated, because there is only limited space defined with inner chimney diameter. The robot has to develop sufficient normal force which is necessary for stabile locomotion. Range of spring deformation is designed for ability to adapt to inner dimension in range from $120 \mathrm{~mm}$ to $200 \mathrm{~mm}$. Ideal solution is modified parallelogram with four springs. This concept allows to overcome obstacles inside chimney.

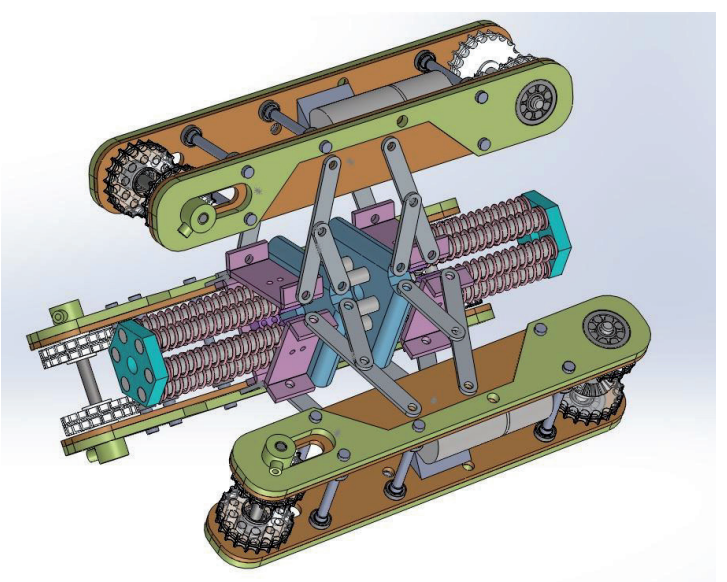

Fig. 4: Frame with tracked segment on two parallelograms. 
The model of the one part of parallelogram is tested for loading inside chimney via using of finite element method (fig. 5). Results on figure 5 shows that designed concept is sufficient.
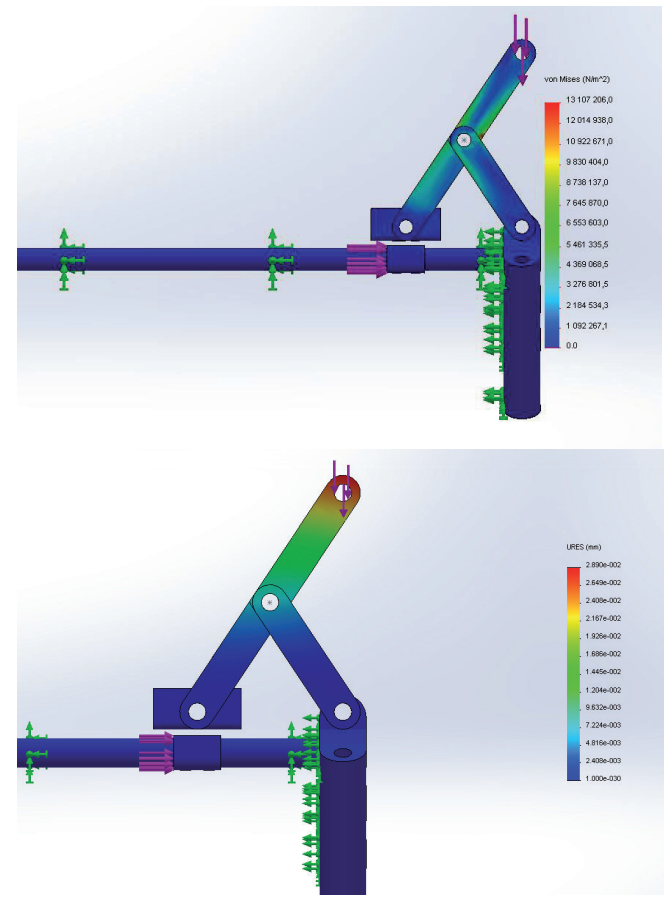

Fig. 5: Simulation of loading of one part of parallelogram (stresses and displacements).

\section{Cleaning module design}

Cleaning process module (fig 6) is connected to main robot body. The shape is designed for collection of dust from inside chimney wall. This module is only for diameter in range from 120 $\mathrm{mm}$ to $150 \mathrm{~mm}$. For other diameters chimney is
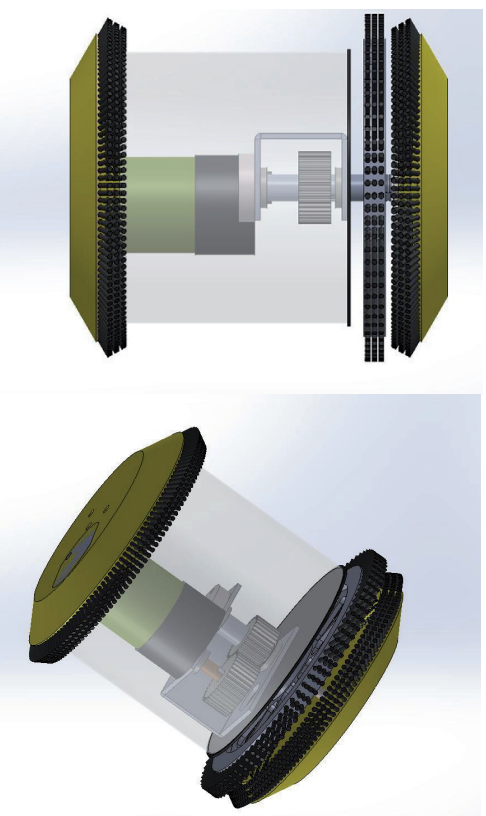

Fig. 6: Cleaning module.

necessary to make another pieces, which will be selected in accordance with cleaned chimney. Brush located on the module rotates around the main axis and it is driven with small DC motor with gearing (fig. 6). This module is located at the bottom on robot body (fig. 7).

\section{Overall concept of the robot}

Figure 7 shows completed model of the robot concept. Camera module is located on the front of robot. Robot consist of two modules with tracks, but it is possible to add another pieces of tracked module for obtaining of higher traction force.

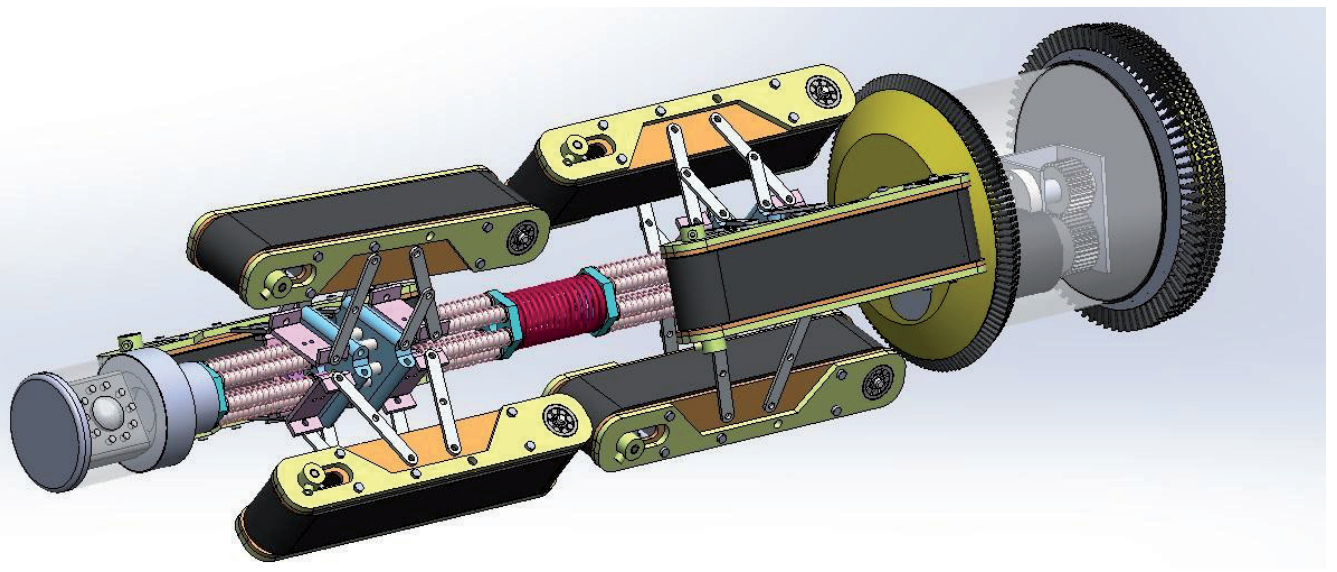

Fig. 7: Completed robot for cleaning and inspection of the chimney. 


\section{Conclusions}

The proposed concept is designed as modular system, which is selectable depending on cleaned chimney. Energy to robot is transferred by wires drawn inside chimney. The main contribution is that robot substitutes the manually cleaning executed by chimney sweeper. If chimney is very long, then it significant proposition, because it reduces risk of any accident on the house top. Mechatronics and robotics seems to be as aid for human in dangerous and complicated works [819].

\section{Acknowledgments \\ The authors would like to thank to Slovak Grant Agency - project VEGA 1/0389/18, VEGA 1/0872/16.}

\section{References and Notes}

[1] Wang Z., Gu H., A Bristle-Based Pipeline Robot for III-Constraint Pipes. IEEE/ASME Transactions on Mechatronics 2008; Vol. 13, No. 3, (2008): 383-392.

[2] Li P., Ma S., Li B., and Wang T., Development of an adaptive mobile robot for in-pipe inspection task. In: Proc. of IEEE International Conference on Mechatronics and Automation. (2007): 3622-3627

[3] Ostertag O., Ostertagová E., Kelemen M., Kelemenová T., Busa J., Virgala I., Miniature Mobile Bristled In-Pipe Machine. International Journal of Advanced Robotic Systems 2014; Vol 11, Issue 12, First Published December 2, 2014. doi $10.5772 / 59499$

[4] Qiao, G., Zhang, Y., Wen, X., Wei, Z., Cui, J. Triple-layered central pattern generator-based controller for 3D locomotion control of snake-like robots. International Journal of Advanced Robotic Systems. Volume: 14 issue: 6, November 1 , 2017. https://doi.org/10.1177/1729881417738101

[5] Qiao J., Shang J. and Goldenberg A., Development of inchworm in-Pipe robot based on self-locking mechanism. IEEE/ ASME Transactions on Mechatronics 2013; 18: 799-806.

[6] Ren T., Liu Q.., Li1 Y., Chen Y., Design, analysis and innovation in variable radius active screw in-pipe drive mechanisms. International Journal of Advanced Robotic Systems 2017; vol. 14, issue 3, First Published May 8, 2017. doi $10.1177 / 1729881417703564$

[7] Yong X., Jianzhong S., Zirong L., Development of controllable two-way self-locking mechanism for micro in-pipe robot. Intelligent Robotics and Applications 2010; 6424: 499-508.

[8] Karavaev, Y. L., Kilin, A. A.: Nonholonomic dynamics and control of a spherical robot with an internal omniwheel platform: Theory and experiments, Proceedings of the Steklov
Institute of Mathematics, Volume 295, Issue 1, 1 November 2016, Pages 158-167

[9] Abramov, I. V., Nikitin Y. R., Abramov, A. I., Sosnovich, E. V. Božek, P.: Control and Diagnostic Model of Brushless Dc Motor. Journal of Electrical Engineering. Volume 65, Issue 5, Pages 277-282, ISSN (Online) 1339-309X, DOl: https://doi. org/10.2478/jee-2014-0044, November 2014

[10] Dekan, M., Duchoň, F., Jurišica, L., Vitko, A., Babinec, A., iRobot Create Used in Education. In: Journal of Mechanics Engineering and Automation. ISSN 2159-5275. Vol. 3, Iss. 4 (2013), s. 197-202.

[11] Hargaš, L., Hrianka, M., Koniar, D., Izák, P.: Quality Assessment SMT Technology by Virtual Instrumentation. Applied Electronics 2007, Pilsen, 5. - 6. 9. 2007, ISBN 987-80-7043-537-3, 2007.

[12] Duchoň, F., Dekan, M., Jurišica, L., Vitko, A.: Some Applications of Laser Rangefinder in Mobile Robotics. In: Journal of Control Engineering and Applied Informatics. - ISSN 14548658. - Vol. 14, No. 2 (2012), s. 50-57

[13] Hanzel, J., Duchoň, F., Rodina, J., Pásztó, P.: Global Navigation Systems for Mobile Robots. In: International Journal of Systems Applications, Engineering \& Development. - ISSN 2074-1308. - Vol. 7, Iss. 5 (2013), s. 279-285.

[14] Tölgyessy, M., Chovanec, L., Pásztó, P., Hubinský, P.: A Plane Based Real-Time Algorithm for Controlling a Semi-Autonomous Robot with Hand Gestures Using the Kinect. In: International Journal of Imaging and Robotics. - ISSN 2231-525X - Vol. 13, Iss. 2 (2014), pp. 126-133.

[15] Hargas, L., Koniar, D., Simonova, A., Hrianka, M., Loncova, Z:: Novel Machine Vision Tools Applied in Biomechatronic Tasks. Procedia Engineering. Volume 96, 2014, pp 148-156.

[16] Spanikova, G., Spanik, P., Frivaldsky, M. et al.: Electric model of liver tissue for investigation of electrosurgical impacts. Electrical Engineering. 2017. Vol. 99. Issue 4. pp 1185-1194. https://doi.org/10.1007/s00202-017-0625-0

[17] Kuric, I., Bulej, V., Saga, M., Pokorný, P.: Development of simulation software for mobile robot path planning within multilayer map system based on metric and topological maps. International Journal of Advanced Robotic Systems. 2017. Vol. 14. Issue 6. pp. 1-14. https://doi. org/10.1177/1729881417743029.

[18] Kelemen, M.: Model Based Design of Mechatronic Systems. Acta Mechanica Slovaca 2017, 21(4):8-9.

[19] Rónai, L., Szabó, T.: Kinematical investigation and regulation of a 4DOF model robot. Acta Mechanica Slovaca 2016, 20(3):50-56 